\title{
Recurrent Adult Soft Tissue Sarcoma
}

National Cancer Institute

\section{Source}

National Cancer Institute. Recurrent Adult Soft Tissue Sarcoma. NCI Thesaurus. Code C7822.

A soft tissue sarcoma occurring in adults that has recurred after a period of remission. 